\title{
Perancangan Interior Politeknik STTT Bandung Program Studi Produksi Garmen
}

\author{
Desty Istiqomalia ${ }^{1}$, Ratri Wulandari², Agustinus Nur Arief Hapsoro ${ }^{3}$ \\ ${ }^{1}$ Mahasiswa Jurusan Desain Interior, Fakultas Industri Kreatif, Telkom University \\ 2,3 Dosen Jurusan Desain Interior, Fakultas Industri Kreatif, Telkom University \\ destyistiqomalia@student.telkomuniversity.ac.id ${ }^{1}$,wulandarir@telkomuniversity.ac.id ${ }^{2}$, \\ ariefhapsoro@telkomuniversity.ac.id ${ }^{3}$
}

\begin{abstract}
ABSTRAK
Dalam rangka menyongsong perkembangan Industri 4.0, fasilitas pembelajaran sekolah ataupun perguruan tinggi memerlukan sebuah perubahan. Fasilitas sebagai sarana dan prasarana pembelajaran berperan penting dalam menciptakan perubahan dalam aspek cara hidup, bekerja, hingga konektivitas dan komunikasi yang diperlukan pada era revolusi 4.0. Seperti yang dikatakan Adedeji dalam Robert (2007) bahwa 'facilities have to be adequate and should be in good condition for schools to function properly.' Namun saat ini masih banyak fasilitas sekolah Indonesia masih belum di perhatikan dengan baik. System pendidikan Indonesia seperti abad 19, pengajar/dosen seperti abad 20, serta peserta didik abad 21" (MENDIKBUD, 2014-2015). Untuk itu di perlukannya pembaharuan guna mengimbangi kemajuan teknologi pada era sekarang ini, dimana segala aktivitas manusia melibatkan kecanggihan teknologi digital berbasis Cyber Phisical System (berbasis data dan cloud computing).

Tujuan perancangan yang akan dilakukan adalah mendesain ruang belajar dengan pendekatan teknologi untuk menciptakan ruang belajar yang terintegritas berbasis muatan teknologi Industri 4.0. Serta Politeknik STTT Bandung, sebagai satu-satunya perguruan tinggi milik pemerintah di bidang tekstil dibawah kementrian perindustrian, dijadikan sebagai objek perancangan.
\end{abstract}

Kata kunci: Industri 4.0; Teknologi; Politeknik STTT Bandung

\section{ABSTRACT}

In order to facing the development of industry 4.0, learning facilities in school or college is require a change. Facilities as infrastucture in school has a big role in creating way of life, work, until innovation of connectivity and creativity that is necessary in Industry 4.0 era. As said Aeji in Robert (2007) that 'facilities have to be adequate and should be in good condition for schools to function properly'. But in fact, until now learning facilities in Indonesia hasn't been concerns properly. Indonesian education system is like $19^{\text {th }}$ century, Teachers are like $20^{\text {th }}$ century, and student are like $21^{\text {th }}$ century'. (MENDIKBUD, 2014-2015). Therefor, require is needed to compensating technological advances in this era, where all human activity involves digital technology based Cyber Phisical System (data dan cloud computing).

The purpose of design is to design learning facilities with technological approach to create integrity study space based on technology industry 4.0. As well as Polytechnic STTT Bandung, the only collage goverenment's under ministry of industry, become objects of design.

Keyword: Industry 4.0; Technology; Polytechnic STTT Bandung

\section{PENDAHULUAN}

Polytechnic Sekolah Tinggi Teknologi Tekstil (STTT) Bandung berdiri sejak tahun 1954. Hingga saat ini Politeknik STTT telah menyelenggarakan 3 program studi salah satunya Produksi Garmen (https://stttekstil.ac.id/9/2/2020). Fokus studi jurusan Produksi Garmen adalah mempelajari tentang rekayasa proses produksi garmen dengan keahlian inti antara lain membuat pola manual dan Computer Assisted Design (CAD), grading pola, analisa pemotongan \& pemanfaatan bahan, teknik menjahit, analisa pemilihan mesin garmen. Program Studi ini juga mempelajari tentang studi gerak dan waktu. Adapun visi Program Studi Produksi 
garmen Politeknik STTT Bandung adalah menjadikan Program Studi Produksi Garmen sebagai acuan dan pusat informasi dalam penyelenggaraan dan pengembangan pendidikan dan pelatihan bidang keahlian produksi garmen. (http://produksigarmen.stttekstil.ac.id/9/2/2020).

Menurut artikel yang diunggah kompas.com pada 3 Juli 2019, dikatakan bahwa pengembangan sumber daya manusia (SDM) merupakan faktor penting dalam menghadapi era revolusi industri 4.0. Untuk itu SDM harus terus di tingkatkan agar tidak ketinggalan dalam menguasai perkembangan teknologi. Dan pendidikan diperlukan sebagai bekal agar SDM tersebut mampu bersaing dengan ketat di era ini. Hal yang sama juga dibahas oleh Lase D (2019) bahwa seiring cepatnya perkembangan tekologi, zaman kini telah memasuki era industri 4.0, dimana menyebabkan dunia pendidikan dituntut untuk bisa menerapkan teknologi dalam proses pembelajarannya sehingga peserta didik mampu berkompetisi dan bersaing didunia kerja pada era ini. Para tenaga pendidikpun dituntut untuk menguasai kecanggihan teknologi.

Dalam merespon hal tersebut Kementerian Perindustrian (2019) dalam situs web resminya mengatakan telah merancang Making Indonesia 4.0 sebagai sebuah roadmap (peta jalan) yang terintegrasi untuk mengimplementasikan sejumlah strategi dalam memasuki era Industry 4.0. Sebagai institusi dibawah kementrian perindustrian, Politeknik STTT Bandung pun ikut setra dalam pengimplementasian program tersebut, dalam program pengembangan terbarunya dikatakan bahwa salah satu capaian program pembelajaran yang akan dibuat adalah menciptakan sistem pendidikan terintegritas berbasis teknologi 4.0.

Untuk merealisasikan visi serta program pembelajaran yang dibuat, tentunya program studi produksi garmen STTT Bandung perlu dilengkapi dengan fasilitas yang baik. Namun menlihat kondisi saat ini, fasilitas seperti system akustik, system pencahayaan, sirkulasi, ergonomi, dan lainnya belum diperhatikan dengan baik. Pun penggunaan teknologi belum diterapkan dengan maksimal, sehingga progam yang dibuat belum bisa di terapkan secara maksimal juga. Seperti dikatakan Chan (1966) "Poor learning facilities can foster negative attitudes just as exceptional design may bolster achievement." Kondisi fasilitas pembelajaran tentunya akan berpengaruh pada student achievement. Untuk itu diperlukannya desain yang mampu menunjang kebutuhan peserta didik dalam pembelajaran di era industry 4.0 ini.

Lase D (2019) menjelaskan juga bahwa era revolusi industri generasi 4.0 ditandai dengan meningkatnya konektivitas, interaksi serta perkembangan sistem digital, kecerdasan artifisial, dan virtual. Untuk itu dalam menjawab permasalahan yang ada, perancangan yang akan dilakukan adalah mendesain ruang belajar dengan pendekatan teknologi hal ini guna menciptakan ruang belajar yang terintegritas berbasis muatan teknologi Industri 4.0.

Pada sisi lain fasilitas program studi Produksi Garmen saat ini tersebar di beberapa lokasi, terbatasnya waktu dan jauhnya jarak yang ditempuh menjadi masalah lain yang ditemukan di Program studi produksi garmen STTT Bandung. Untuk itu perancangan baru akan dilakukan guna memaksimalkan efisiensi waktu dalam proses pembelajaran.

\section{METODE PENELITIAN}

Dalam perancangan Program Studi Produksi Garmen STTT Bandung ini dibutuhkan datadata serta informasi yang lengkap, relevan dan jelas untuk menghasilkan output yang sesuai, maka dalam proses penyusunan perancangan menggunakan metode antara lain:

\section{A. Pengumpulan Data}

1. Data Primer

Proses collecting data primer perancangan dengan melakukan peninjauan langsung objek terkait untuk mendapatkan data yang berhubungan langsung dengan Program Studi Produksi Garmen Politenik STTT meliputi pengumpulan data yang berhubungan dengan objek perancangan dan masalah pada objek perancangan. Pengumpulan data-data yang dibutuhkan 
untuk desain interior ruang belajar yang terdapat di kampus Program Studi Produksi Garmen Politeknik STTT dilakukan dengan cara:

- Wawancara

a. Dengan pihak Program Studi Produksi Garmen STTT Bandung sebagai objek utama, untuk mengetahui lebih jelas mengenai program pendidikan dan hal-hal yang terkait perancangan objek (pendidikan vokasi) dengan rumpun ilmu teknik penerbangan atau kedirgantaraan.

b. Dengan mahasiswa/i untuk mengetahui aktivitas dan kebutuhan fisik maupun psikis pengguna yang diperlukan dalam sebuah lembaga pendidikan vokasi dengan rumpun ilmu kedirgantaraan.

- Studi Lapangan/Survey

Melakukan studi banding pada objek yang sejenis yang mengamati lokasi dan mengidentifikasi kegiatan yang terjadi sebagai dasar pertimbangan dalam pengelompokan kebutuhan dan pembuatan konsep. Melakukan pengamatan survey secara langsung ke lembagalembaga pendidikan vokasi sejenis sebagai referensi perbandingan antara lembaga pendidikan tersebut. Observasi dilakukan untuk mendapatkan data manusia berupa aktivitas pengguna dan kapasitas pengguna, program ruang, fasilitas dan lain-lain.

\section{Data Sekunder (Studi Kepustakaan)}

Melalui studi literatur dari buku dan lain sebagainya yang berhubungan dengan perancangan ulang Program Studi Produksi Garmen STTT Bandung baik untuk standar, teknis, maupun efek yang akan ditimbulkan untuk melengkapi informasi yang dibutuhkan. Data-data yang dibutuhkan seperti definisi, klasifikasi, standarisasi, serta faktor pendukung lain tentang sarana pendidikan yang didapat dari buku-buku literatur seperti: Buku Data Arsitek Jilid 1, 2, \& 3 karya Ernest Neufert; Buku Dimensi Manusia, beberapa majalah online, dan jurnal-jurnal perancangan terkait pendidikan tinggi.

\section{B. Analisa Data}

Analisis data diperoleh dari hasil survey dan wawancara dengan pihak terkait mengenai permasalahan yang ada di Politeknik STTT Bandung Program studi Produksi Garmen. Dari hasil analisa didapatkan penyelesaian ataupun solusi.

\section{Sintesis}

Melaui data dan analisis permasalahan Politeknik STTT Bandung Program Studi Produksi Garmen Fasilitas pembelajaran belum mampu menunjang pembelajaran 4.0 serta masih belum sesuai dengan visi yang ingin dicapai. Dari permasalaha yang ada dikembangkan kedalam sebuah tema Tri Color Geometry dan konsep Technological Harmony melalui perancangan Politeknik STTT Bandung Program Studi Produksi Garmen.

\section{HASIL PENELITIAN DAN PEMBAHASAN}

\section{A. Tema Perancangan}

Tri Color Geometri merupakan sebuah tema yang diangkat dimana perancangan didominasi oleh 3 warna yang dapat meningkatkan kerjasama dan kreatifitas yang dikombinasikan dengan bentuk geometri. Bentuk geometri yang dipakai merupakan bentuk dasar honeycomb yang dikembangkan. Bentuk dasar honeycomb sendiri diangkat sebagai bentuk yang dapat mempresentasikan sebuah kecanggihan teknologi. Dalam hal ini tema yang diangkat diharapkan dapat menggambarkan visual teknologi dalam desain perancangan. 
Adapun suasana yang ingin dicapai adalah suasana yang dapat menghadirkan kesan ruang diantaranya fleksible in learning, smart, dan innovative. Juga tentunya menggambarkan kecanggihan dan kemudahan dalam menggunakan teknologi.

\section{B. Konsep Perancangan}

Politeknik STTT Bandung program studi produksi garmen merupakan sekolah tinggi berbasis teknologi. Institusi ini diharapkan mampu berperan sebagai acuan dan pusat informasi di bidang industri garmen. Adapun melihat kondisi saat ini dunia sedang memasuki era 4.0 dimana kita dituntut untuk dapat menguasai teknologi di segala aspek kehidupan termasuk dalam proses belajar. Hal ini tidak lain agar kita lebih terlatih dan mampu bersaing di dunia luar.

Konsep yang akan digunakan dalam perancangan Politeknik STTT Bandung Program studi Garmen ini adalah "Technological Harmony" dimana menggabungkan brand strategy, textile technology, artificial intelligence, dan internet of things kedalam desain interior, tidak hanya sebagai elemen estetis tetapi juga sebagai sistem dan juga edukasi. Technological Harmony dihadirkan untuk memenuhi kebutuhan serta gambaran/citra dari kecanggihan teknologi di era Industry 4.0.

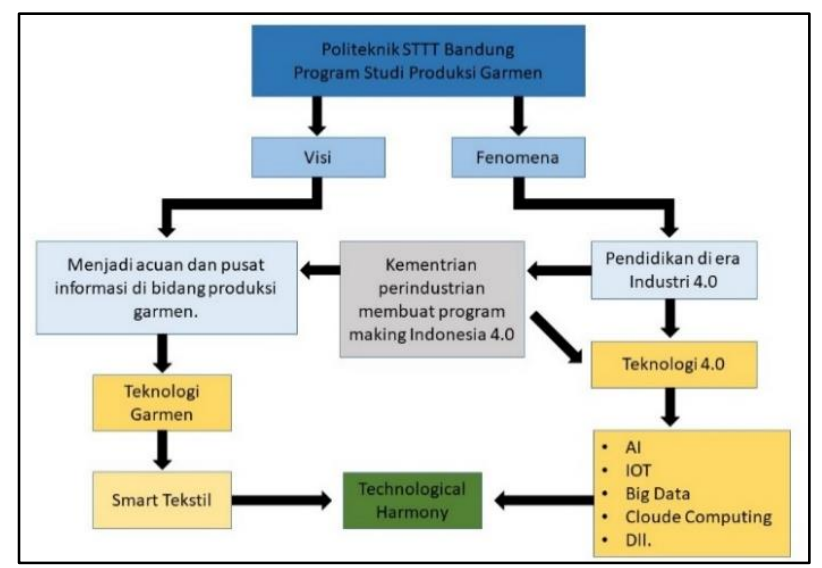

Gambar 1. Kerangka Berfikir Desain Sumber: Data Pribadi (2020)

\section{Konsep Organisasi Ruang}

Pola sirkulasi dalam ruang diatur berdasarkan kebutuhan aktivitas, pengguna dalam ruang, serta kondisi eksisting. Adapun sirkulasi yang digunakan antara lain:

\section{- $\quad$ Sirkulasi Linier}

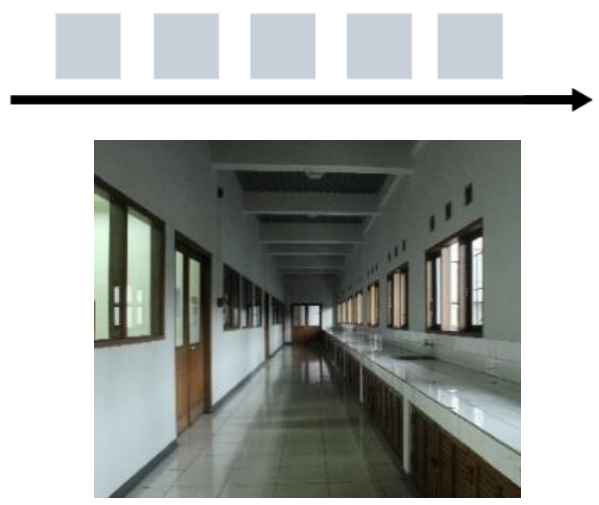

Gambar 2. Sirkulasi Linier Sumber: Dokumentasi Pribadi (2020) 
- $\quad$ Sirkulasi Network
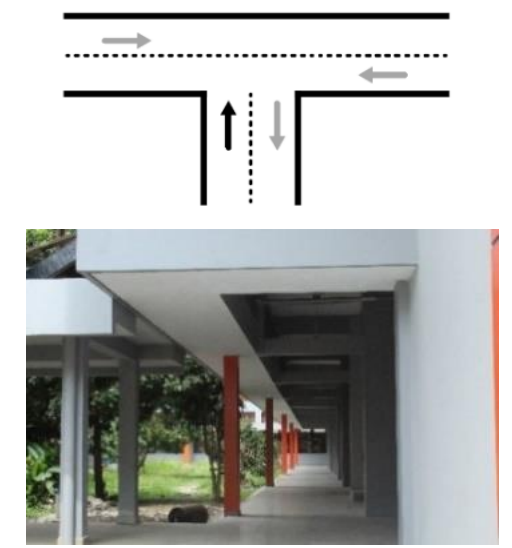

Gambar 3. Sirkulasi Networking Sumber: Dokumentasi Pribadi (2020)

\section{Konsep Bentuk}

Konsep bentuk dalam interior mempresentasikan sebuah citra dari suasana dalam ruang. Untuk itu dalam menghadirkan suasana dengan tema "Technological Harmoni" yang diusung, bentuk dasar yang akan diterapkan mengadopsi dari bentuk yang mempresentasikan sebuah teknologi yaitu honeycomb. Texture Honeycomb sendiri banyak digunakan sebagai technology background yaitu sebagai bentuk yang mempresentasikan sebuah kecanggihan teknologi. Adapun bentuk dasar dari honeycomb adalah segi 6. Dari bentuk dasar tersebut juga akan dikembangkan dan kemudian di implementasikan pada elemen pembentuk ruang ataupun furniture.

\section{Konsep Warna}

Warna yang digunakan dalam perancangan adalah warna warna yang dapat meningkatkan kerjasama dan kreatifitas. Adapun teknik yang digunakan adalah Analogus dimana menggunakan warna warna berdekatan dalam roda warna. Adapun warna yang digunakan antara lain, Orange - Kuning - Hijau - Biru - Hitam - Abu.

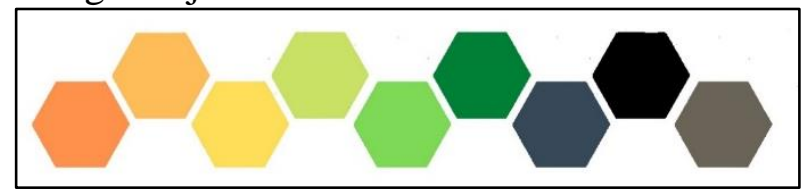

Gambar 4. Tone Warna

Sumber: Dokumentasi Pribadi (2020)

4. Konsep Pencahayaan \& Penghawaan

Pencahayaan dalam ruang dilengkapi dengan sensor Airduno Uno 3. Sensor ini dirancang menjadi suatu sistem yang akan mendeteksi suhu dan cahaya yang masuk kedalam ruang sehingga kebutuhan penghawaan dan pencahayaan dapat diatur sesuai kebutuhan dan keadaan. Sensor akan ditempatkan pada meja dosen. Sehingga saat proses pembelajaran dosen dapat mengatur kondisi ruang dengan mudah (Dosen bisa mengatur pengaturan awal sensor sehingga sensor bekerja lebih optimal serta konsisi ruang dapat dicapai sesuai dengan yang diharapakan). Adapun untuk memenuhi kebutuhan pencahayaan tersebut digunakan pencahayaan alami serta perncahayaan buatan yaitu general lighting dan task lighting. 


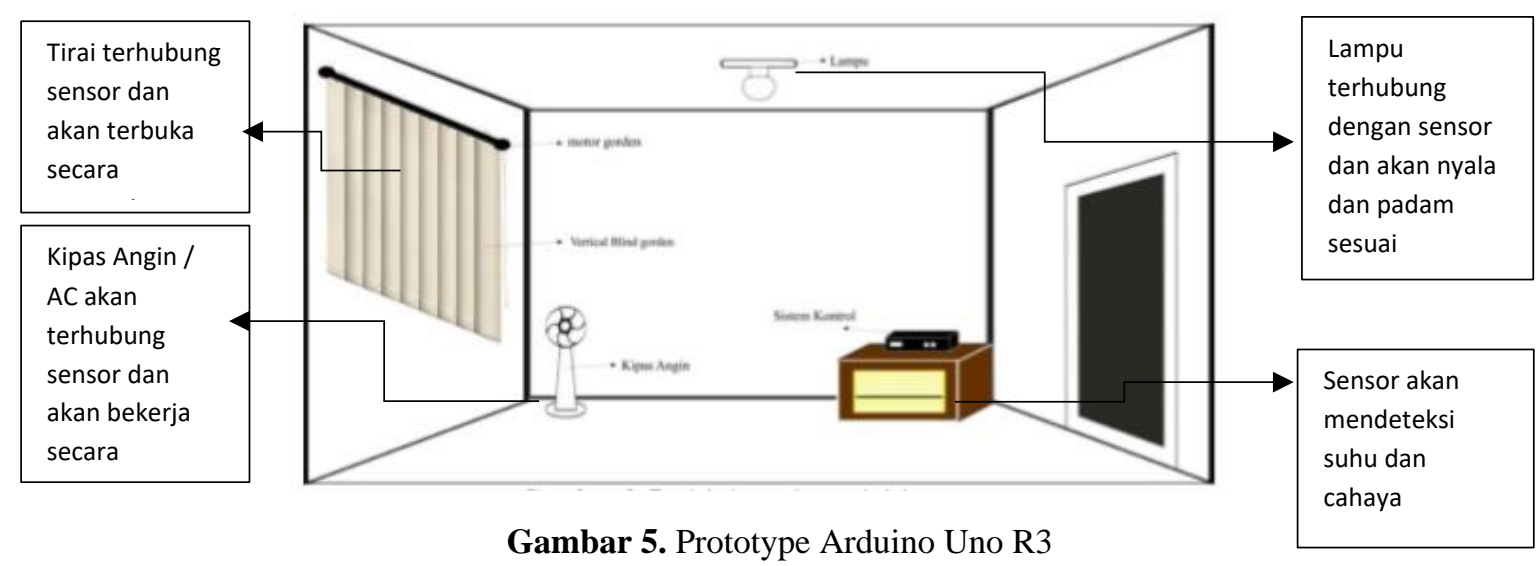

Sumber: Jurnal (2020)

\section{Konsep Furniture}

Kegiatan belajar di era industri 4.0 sangatlah bervariatif. Baik secara group maupun individu, formal maupun non formal dan sebagainya. Untuk itu furniture yag digunakan ialah yang dapat menyesuaikan sesuai kondisi/mode pembelajaran yang diharapkan. Serta furniture dilengkapi dengan teknologi AI dan IoT. Hal ini bertujuan untuk menunjang serta memudahkan aktifitas dalan ruang dan memberikan kesan ruang yang tidak kaku. Adapun dalam memenuhi kebutuhan pembelajaran di era 4.0.

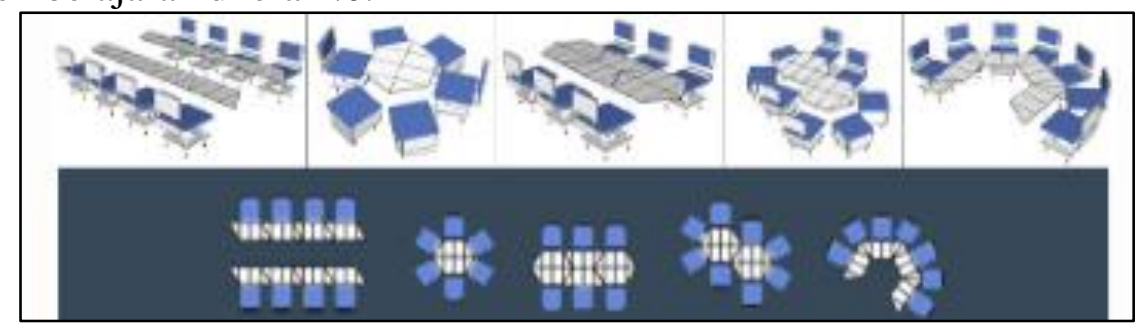

Gambar 6. Konsep Mikro Ruang Kelas Teori Sumber: Dokumentasi Pribadi (2020)

\section{Solusi Desain}

1. Ruang Kelas Teori

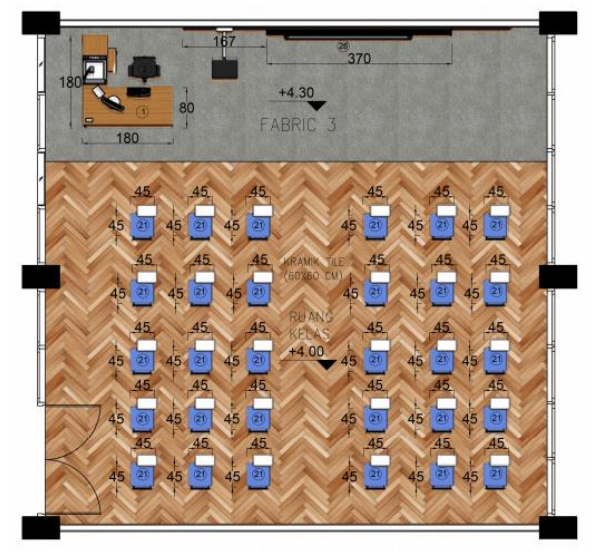

Gambar 7. Layout Ruang Kelas Teori Sumber: Dokumentasi Pribadi (2020) 
Berdasarkan silabus dalam kurikulum yang berlaku, ruang kelas teori ini digunakan sebagai sarana dalam pembelajaran teori guna meningkatkan keterampilan serta pengetahuan teori berkaitan dengan mata kuliah penunjang yang bersangkutan. Dalam pembelajarannya dilakukan secara individu maupun grup. Untuk itu ruang kelas ini dirancang untuk dapat digunakan dalam segala mode pembelajaran dalam kelas. Ruang kelas dilengkapi dengan interaktif board serta digunakan pula sensor Arduino Uno R3 untuk mengatur pengkonsisian ruang agar selalu dalam kondisi yang diharapkan.

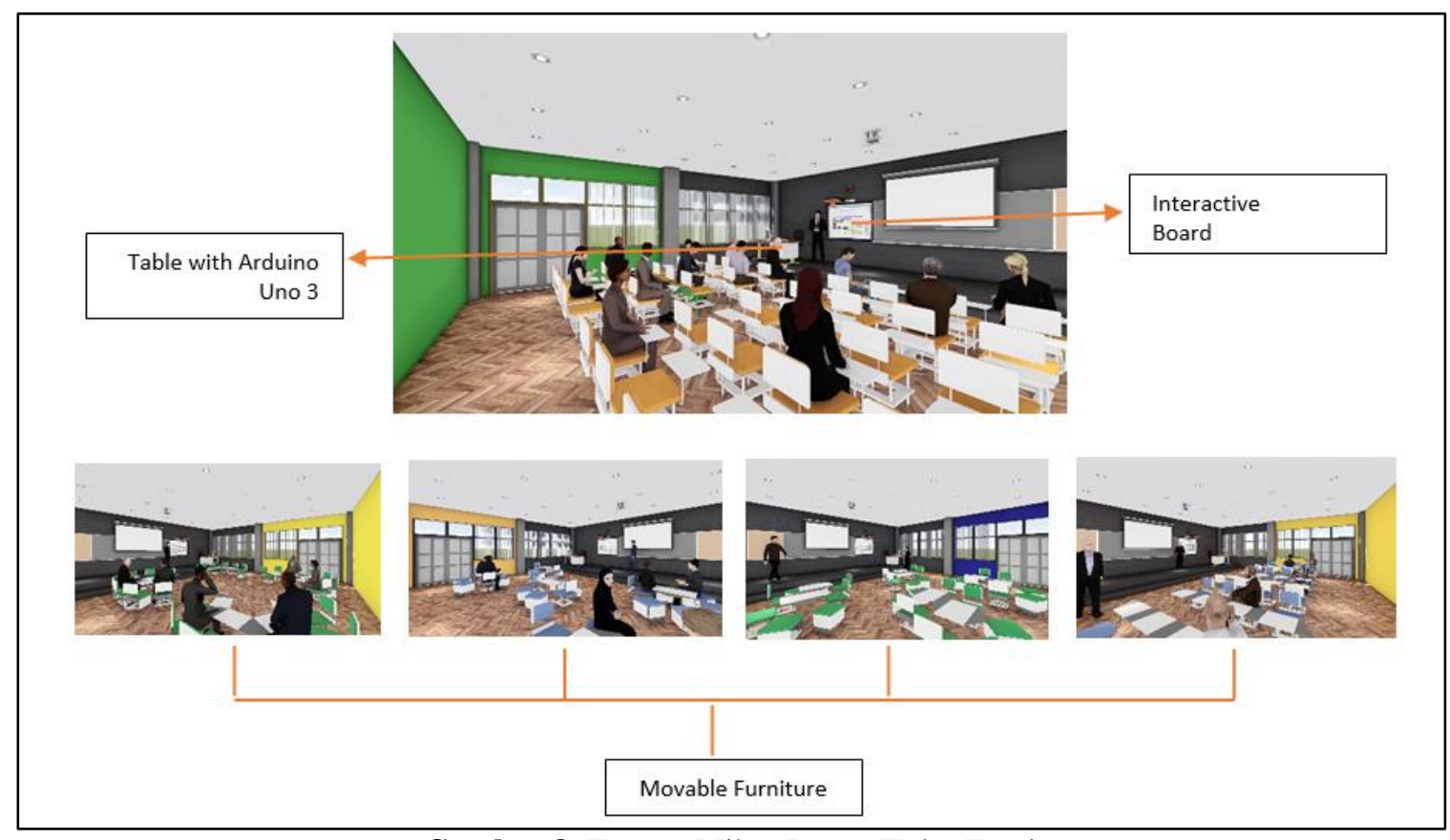

Gambar 8. Konsep Mikro Ruang Kelas Teori

Sumber: Dokumentasi Pribadi (2020)

\section{Ruang Studio Fashion}

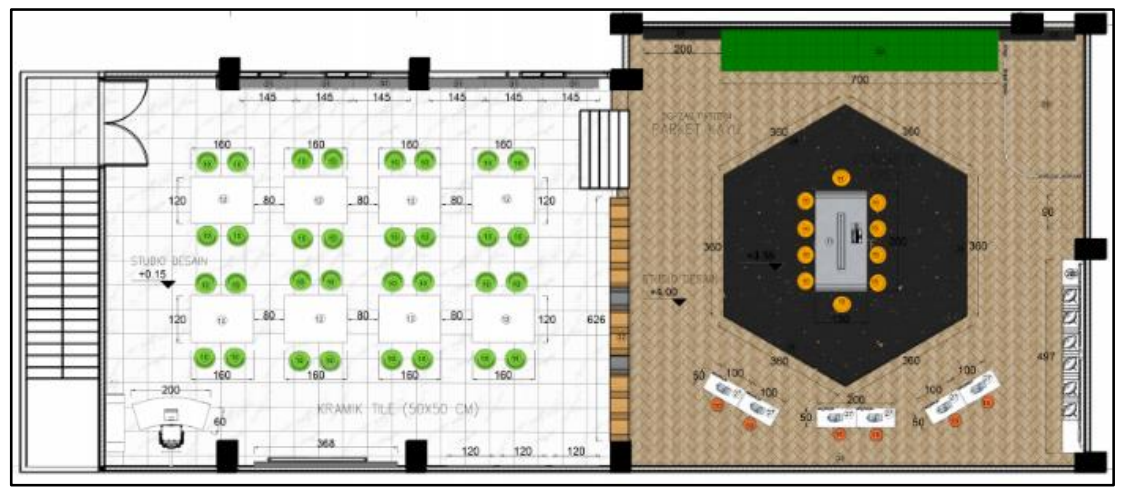

Gambar 9. Studio Fashion

Sumber: Dokumentasi Pribadi (2020)

Studio desain digunakan sebagai pusat pembelajaran fashion desain. Dalam ruang ini mahasiswa melakukan berbagai kegiatan yang berhubungan dengan pembelajaran fashion desain seperti menggambar dasar, fotografi, mofifikasi desain dan lain sebagainya. Untuk itu ruangan ini didesain dengan ruang diskusi yang dilengkapi dengan area menjahit, display 
pakaian, dan ruang ganti pakaian. Dalam memnuhi kebutuhan dalam ruang, area ini dilengkapi dengan interactive board, interactive table, wall display, drawing wall, dan fitting room.

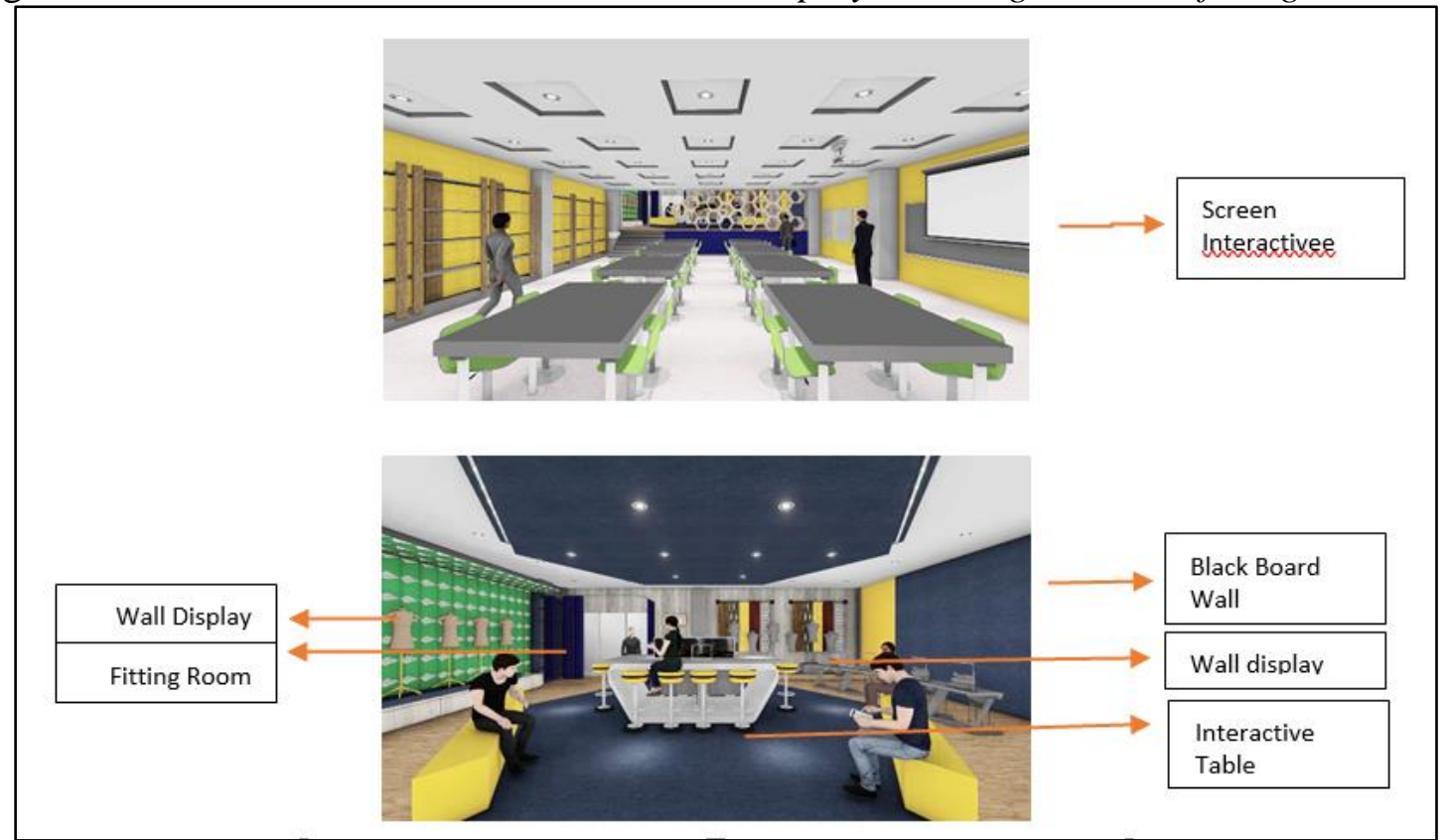

Gambar 10. Konsep Mikro Studio Desain

Sumber: Dokumentasi Pribadi (2020)

\section{Ruang Workshop Penjahitan}

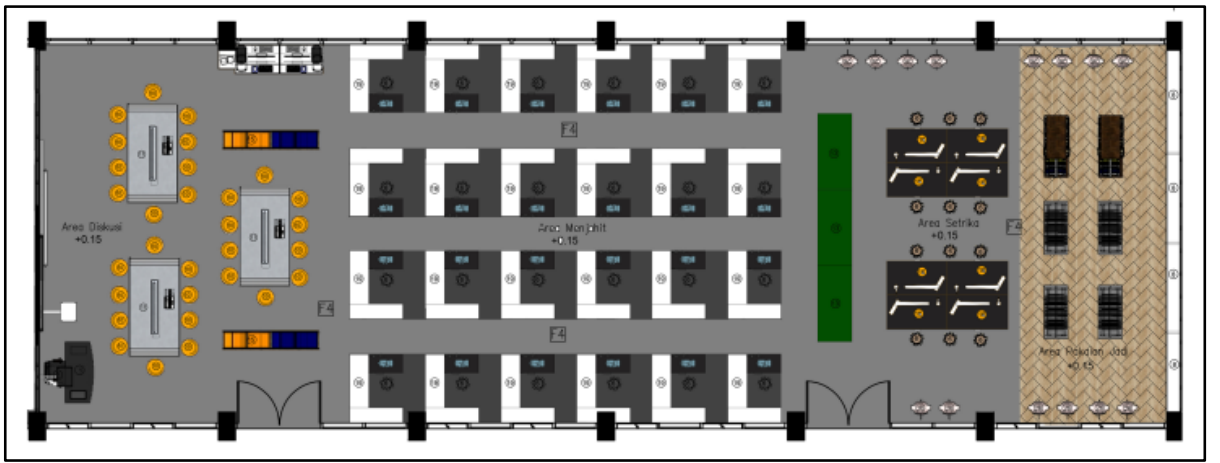

Gambar 11. Workshop Penjahitan

Sumber: Dokumentasi Pribadi (2020)

Workshop penjahitan mempelajari tentang pengolahan tekstil dari potongan bahan kain hingga pakaian jadi. Adapun prosesnya dimulai dari menjahit potongan bahan, hingga melipat pakaian jadi. Untuk itu dalam perancangan ini, rung dibagi menjadi beberapa area diantaranya menjahit, menyetrika, diskusi, dan area untuk pakaian jadi. Area penjahitan ditempatkan disisi ruang dekat dengan storage builtin pada dinding hal ini dilakukan agar kebutuhan bahan serta alat dapat diakses dengan mudah saat proses pembelajaran menjahit berlangsung. Area diskusi ditempatkan di tengah ruang untuk memaksialkan komunikasi dan interaksi antar pengguna ruang. Adapun area setrikan ditempatkan dikedua sisi ruang.

Ruang dilengkapi dengan interactive board, Interactive screen, interctive table, built in storage, dan control machine area. Meja penjahitan juga dilengkapi dengan sensor storage untuk memudahkan proses penjahitan. 


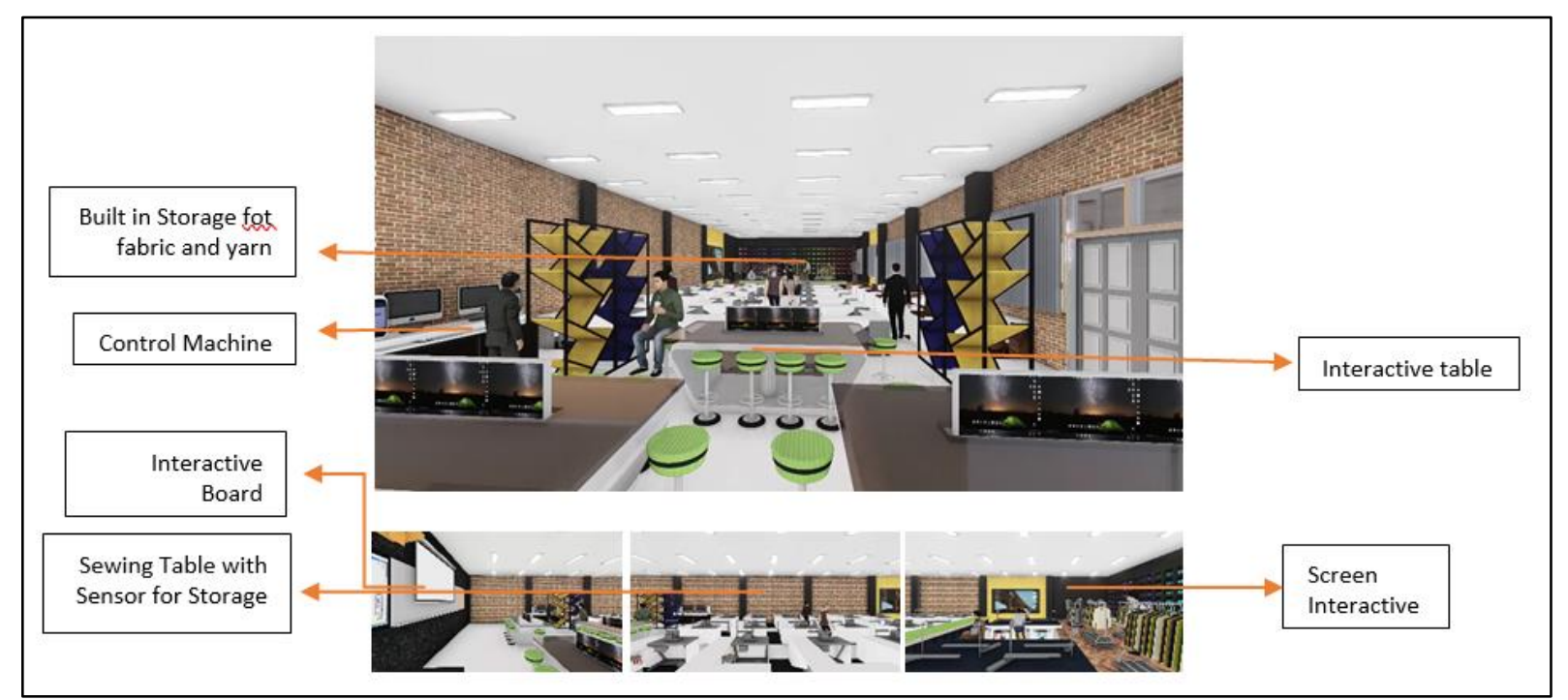

Gambar 12. Konsep Mikro Workshop Penjahitan Sumber: Dokumentasi Pribadi (2020)

\section{Ruang Workshop Cutting}

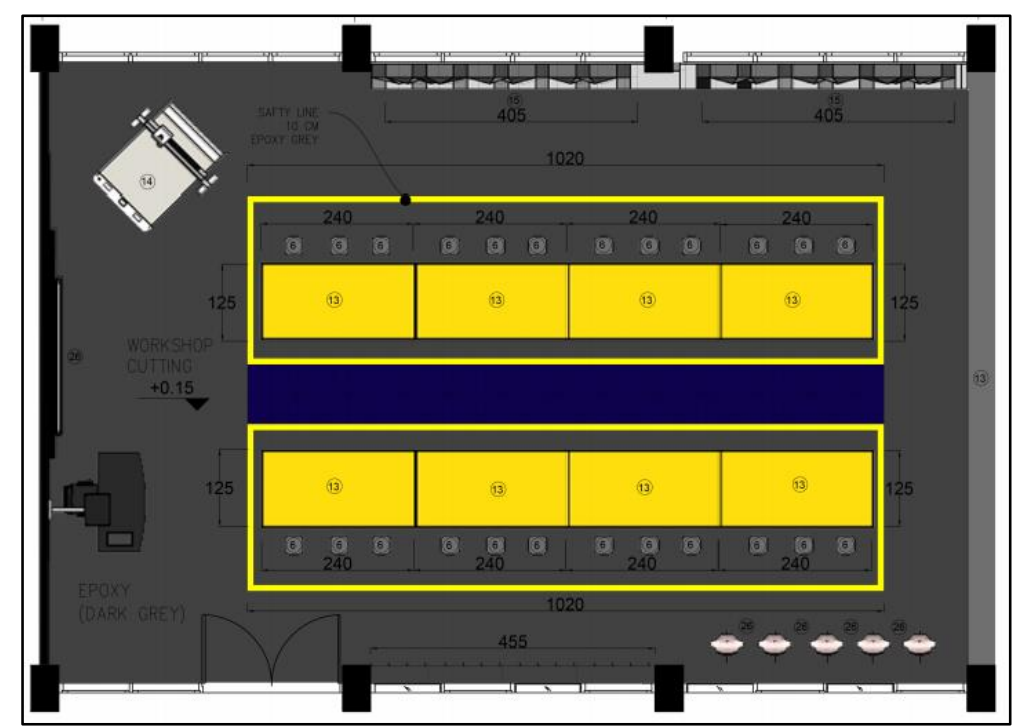

Gambar 13. Konsep Mikro Studio Desain Sumber: Dokumentasi Pribadi (2020)

Workshop cutting diharapkan mampu menunjang pembelajaran pemotongan bahan dimana kegiatan yang dilakukan diantaranya menganalisa pemotongan bahan, pemeriksaan bahan baku, perhitungan kebutuhan bahan, marking, spreading, costing, meletakan bahan/ kain, serta kain, perencanaan layout pola, menggunakan bahan/ kaint, teknik pemotongan, prosedur pengawasan kualitas, pengikatan, pemasangan tiket dan penyimpanan. Guna menunjang kebutuhan tersebut ruang kelas ini dirancang dilengkapi dengan bench serta tanaman dengan media Hydroponik textil agar kelas lebih menarik dan tidak membosankan, tanaman dalam juga dapat meminimalisir debu halus dalam ruang akibat cutting kain. 


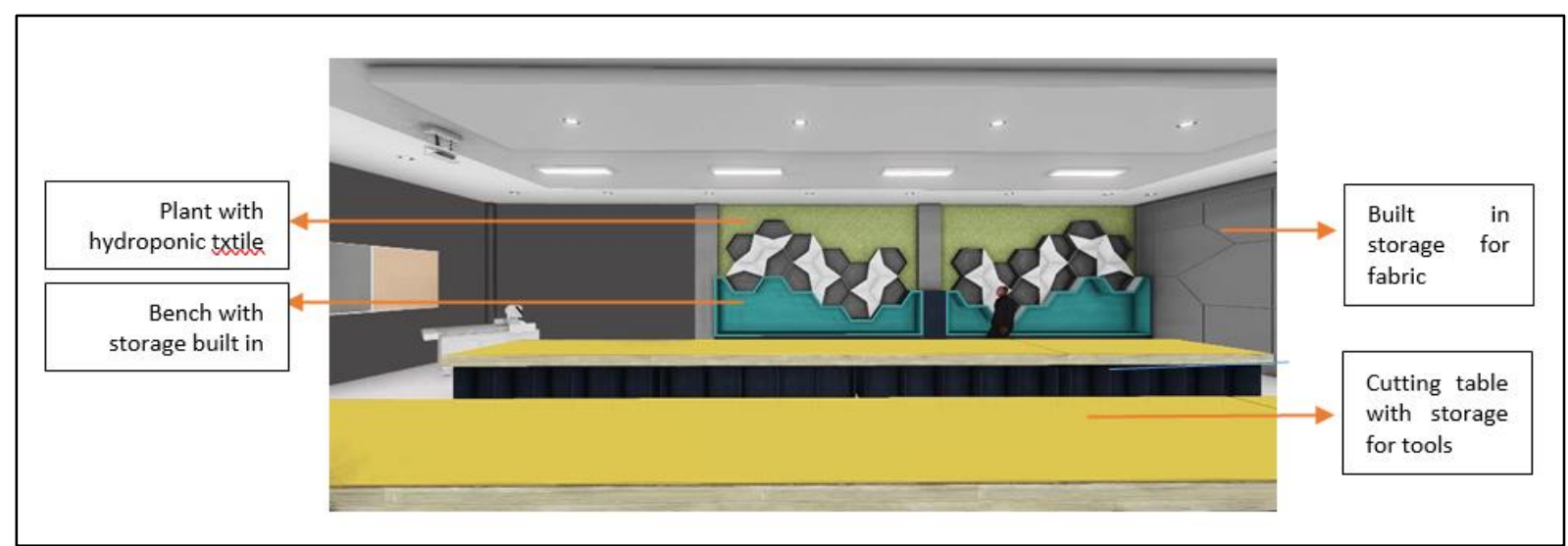

Gambar 14. Konsep Mikro Workshop Cutting Sumber: Dokumentasi Pribadi (2020)

\section{Ruang Fungsi Kantor}

Ruang fungsi kantor terdiri dari ruang dosen, Ka. Lab, dan area meeting/diskusi, Ruang dosen merupakan area bekerja diluar mengajar bagi para dosen, area ini digunakan selama jam kerja dari pukul 08.00-16.00. Kegiatan yang dilakukan antara lain memeriksa tugas mahasiswa, menyusun laporan, membuat kurikulum serta kegiatan sejenis lainnya. Ruang ini juga biasa digunaka untuk kegiatan meeting ataupun diskusi ringan. Untuk itu dalam perancangan, ruang ini didesain seraca nyaman dengan dilengkapi ruang rapat yang santai serta mini bar sebagai sarana penunjang.

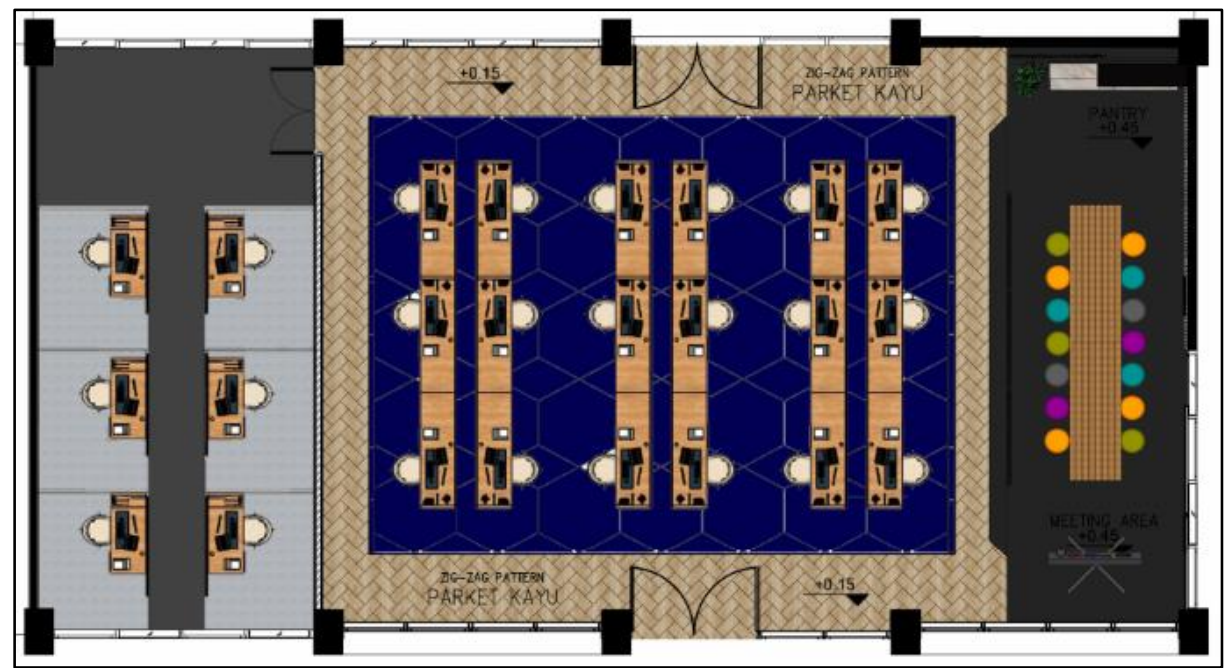

Gambar 15. Layout Ruang Kantor

Sumber: Dokumentasi Pribadi (2020)

Area rapat dan diskusi ditempatkan di tengah ruang juga untuk memaksialkan komunikasi dan interaksi antar pengguna ruang. Adapun area KA. Lab dibuat secara kubikel agar setiap pengguna tetap memiliki privasinya sendiri. 


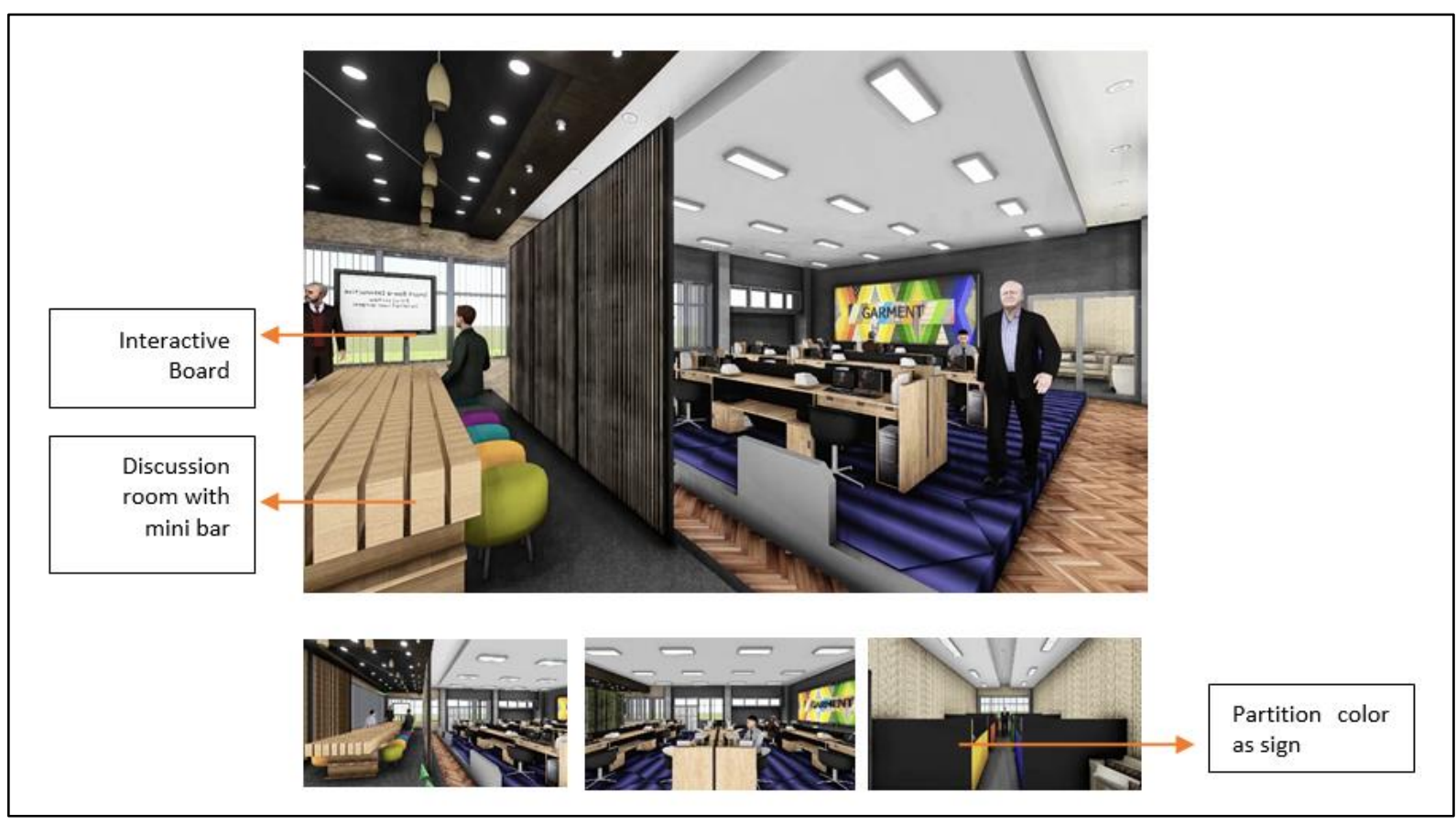

Gambar 16. Konsep Mikro Ruang Kantor Sumber: Dokumentasi Pribadi (2020)

\section{KESIMPULAN}

Berangkat dari fenomena yang ada saat ini yaitu Industry 4.0 yang juga berdampak pada dunia pendidikan, Technological Harmony dihadirkan untuk memenuhi kebutuhan pembelajaran di era Industry 4.0. Adapun dalam hal ini Politeknik STTT Bandung Program Studi Produksi Garmen menjadi objek perancangan. Pendekatan teknologi juga digunakan untuk memenuhi kebutuhan serta permasalahan internal dari objek perancangan. Textile technology serta technology 4.0 diaplikasikan kedalam desain interior seperti dinding, ceiling dan furniture tidak lain untuk memenuhi kebutuhan serta memudahkan peroses pembelajaran.

\section{DAFTAR PUSTAKA}

Addington, M., Schodek, D. (2005). Smart materials and new technologies. Burlington, MA, USA: Elsevier.

Daniel D. Watch., Perkins \& Will (2001). Building Type Basic for Research Laboratories: New York, Chichester, Weinheim, Brisbane, Singapore, Toronto.

Hujair AH. Sanaky (2009) Media Pembelajaran. Yogyakarta: Safiria Insania Press.

Kompas.com, "Hadapi Revolusi Industri 4.0, Pendidikan Jadi Kunci Pengembangan Diri", https://edukasi.kompas.com/read/2019/07/03/19144701/hadapi-revolusi-industri-40pendidikan-jadi-kunci-pengembangan-diri. [accessed Feb 2 2020]

Mogensen, J. E., \& Jørgensen, P-E. (2016). Hydrophobic textiles in hospital design - a study on the cleaning and disinfection possibilities of coated textiles in hospital interior design. Abstract from TCL 2016: International Conference on Textile Coating and Laminating, Prague, Czech Republic.

Ngafifi, M. (2014). Kemajuan Teknologi Dan Pola Hidup Manusia dalam Perspektif Sosial Budaya. Jurnal Pembangunan Pendidikan: Fondasi Dan Aplikasi

PENGEMBANGAN MEDIA PEMBELAJARAN BERBASIS TEKNOLOGI INFORMASI. Available from: https://www.researchgate.net/publication/296704617_ 
Desty Istiqomalia, Ratri Wulandari, Agustinus Nur Arief Hapsoro

Perancangan Interior Politeknik STTT Bandung Program Studi Produksi Garmen

PENGEMBANGAN_MEDIA_PEMBELAJARAN_BERBASIS_TEKNOLOGI_INFO RMASI [accessed Feb 23 2020]

https://stttekstil.ac.id/profile/ [accessed Feb 2 2020] 